\title{
The Effectiveness and Related Factors of Taiwan's Long-Term Care Professional Manpower Training (Level I Common Curriculum)
}

\author{
Meei-Shiow Lu', Ching-Min Chen ${ }^{2}$, Chung-I Huang ${ }^{3,4,5^{*}}$, Li-Chu Wu ${ }^{6}$ and Yao-Hua Wang ${ }^{7}$ \\ ${ }^{1}$ The National Union of Nurses' Associations, ROC, Taiwan \\ ${ }^{2}$ Department of Nursing, National Cheg-Kung University, Taiwan \\ ${ }^{3}$ Joint Commission of Taiwan, Taiwan \\ ${ }^{4}$ School of Health Care Administration, Taipei Medical University, Taiwan \\ ${ }^{5}$ Department of Technology Application and Human Resource Development, National Taiwan Normal \\ University, Taiwan \\ ${ }^{6}$ Institute of Health Policy and Management, College of Public Health, National Taiwan University, Taiwan \\ 7 Information Technology Center, National Taiwan Normal University, Taiwan
}

*Corresponding author: Chung-I Huang, Deputy Executive Officer, Joint Commission of Taiwan; Adjunct Lecturer, School of Health Care Administration, Taipei Medical University; Doctoral Candidate, Department of Technology Application and Human Resource Development, National Taiwan Normal University, Taiwan, Tel: +886-2-89643000 ext.3903, Fax: +8862-29634022,E-mail: turbo@tmu.edu.tw

\section{Abstract}

In view of the increase in demand for long term care professionals, the Department of Health in Taiwan has launched a training program for long term care professionals in 2010 and has entrusted the National Union of Nurses Association in Taiwan to carry out the Level I 18-hour long term care professionals training scheme. Training lessons commenced from May till July in 2011 and the teaching materials are certified by professionals and Delphi technique. Training lessons will be taught in a lecture and trainees will include medical professionals, social workers and clinical psychologist. There will also be assessment before and after classes to ensure the quality of the training program which consists of a total of 1963 trainees.

The passing rate of the training program is more than $97 \%$. A total of 851 completed the after-class analysis and results have shown that the after-class assessment results is significantly better than before class analysis assessment $(p<$ 0.001 ). This has proved that the training class has significantly improved the knowledge and ability of the trainee towards long term caring and allowing trainees of different occupation to have the same amount of knowledge and understanding.

The main objection of Level I lessons is to build up the basic knowledge of the trainees in the field of long-term care before they start on their practical work. The class experience will be used in planning and executing further training after trainees arrive at their new job post.
\end{abstract}

\section{Keywords \\ Long-term care, Manpower training, Professional training, Effectiveness, Curriculum assessment}

\section{Background}

The Department of Health, Executive Yuan in Taiwan has launched a long-term care plan for the elderly in 1998. One of the main objectives of the plan is to set up an integrated service network and launch a long-term care management demonstration center with a "single window" policy. This allows long-term care cases to receive professional evaluation and case management for proper scheduling of individual cases. At the same time, in a plan proposed in 2002 to promote care service welfare and industrial development, care management is included as one of the main objectives. The governing bodies of every county and city are made responsible for the setting up of long-term care management centers to gather funds and managing individual cases of long-term care. However, various long-term care management demonstration centers have already been set up a few years ago by the Department of Health,

Citation: Meei-Shiow L, Ching-Min C, Chung-I H, Li-Chu W, Yao-Hua W (2018) The Effectiveness and Related Factors of Taiwan's Long-Term Care Professional Manpower Training (Level I Common Curriculum). Int Arch Nurs Health Care 4:094. doi.org/10.23937/2469-5823/1510094

Accepted: May 26, 2018: Published: May 28, 2018

Copyright: (c) 2018 Meei-Shiow L, et al. This is an open-access article distributed under the terms of the Creative Commons Attribution License, which permits unrestricted use, distribution, and reproduction in any medium, provided the original author and source are credited. 
causing two of the same care management centers to appear in every county and city. In the second meeting by the Council of Social Welfare Promotion on May $24^{\text {th }}$, 2005 , it has been concluded that all care management centers shall be named Long-term Care Management Centers for the benefits of facilitating.

The Executive Yuan council has regarded the "Setup Long-term care 10 year-plan" as the flagship plan for the "Enhance nursing for the disabled" scheme in September 2006 with the basic objective of "Setting up a complete Long-term care system to ensure disabled people receive suitable services. This will enhance their independent living capability and improve their quality of life and self-esteem". The secondary objective will include "providing long-term nursing services that will suit the public's needs and therefore providing better rights for the public when choosing their nursing options". In order to meet the objectives, the most straight forward strategy is to train highly qualified people for areas of work that are most desired for elder's health and social care. The training of highly qualified professionals for the medical, personal care and social care areas will meet the needs of the needed and provide a more complete health care services.

The main objective of this paper is to investigate the effect of the Level I training program and the effect of the demographics of the trainees on the program. The analysis results of this paper will be able to provide a reference for future training programs of the same nature.

\section{Literature Review}

\section{Current situation}

Past experience of developed countries has accurately pointed out that an ageing population has led to a rapid increase in disabled people and people infected with chronic disease. This trend produced a huge demand for workers for long-term care [1]. In the $21^{\text {st }}$ century, the ratio of elders (65-years-old and above) in Taiwan has increased from $7 \%$ of the total population in 1993 to $10.74 \%$ of the total population in 2011 [2]. Looking into an example in USA, even though the number of elderlies takes up $12 \%$ of the total population, the amount of funds allocated for the elders takes up $1 / 3$ of the nation's total medical funds. Further analysis has shown out that $40 \%$ of the funds are used on nursing homes and home care or other long-term care services that are not related to chronic disease medical service [1]. Looking back at Taiwan, it is estimated that by the year 2030 , up to $20 \%$ of Taiwan's population will consist of elderlies and more than half of the total medical funds will be allocated for the elderly population, thus showing the massive demand for medical funds for the elderly [3].

According to the 2005 survey on the situation of elderlies conducted by Ministry of Interior, the Taiwan public emphasized most on 5 long-term care services: Care service for elderly living alone (71.43\%), elderly day care service $(68.37 \%)$, institutional respite care $(67.60 \%)$, home care services $(67.60 \%)$ and home nursing $(67.21 \%)$ [4]. It can be deduced that the needs for long-term care are oriented. Therefore, in terms of human resource development, professionals from various categories including medical, nursing, rehabilitation, nutritional and medicinal are needed to participate, thus expanding training in the field of health care. The estimation of the minimum requirement for the size of the workforce for each category is as shown: Care management (934 2210); care management instructor (334 684); nursing (627 3745) and physical and occupational therapist (191 782) [4].

\section{Training program in Taiwan}

In response to the increase in demand for long-term care workers, the department of health has launched a training program for long-term care workers in 2010. In order to ensure the training program will progress with consistency and achieve its objective, the Department of Health, Executive Yuan has invited organizations and experts to call a meeting. Training classes for the program will be discussed and planned in the meeting. Classes will be divided into long-term care workers training classes and long-term management center workers training classes. Long-term care workers training classes are further divided into 3 stages [4]: (1) Level 1 class with a total of 18 hours. The main objective of this stage is to ensure all workers in the field of long-term care will be equipped with the basic knowledge of long-term care concept. Long-term care workers are also required to complete Level 1 class within six months of commencement of their jobs. (2) Level II professional class with a total of 24-32 hours. In response to the different requirements by different service fields, every field will customize their own set of training courses. These courses will develop the skills of workers in their own individual field and will emphasize on professional care ability. The Level II professional class will be completed within 2 years after commencement of work. (3) Level III training class will last for a total of 24 hours. The curriculum will provide an all-rounded class across the fields and will emphasize more on improving service quality. Trainees are also expected to communicate with other professional workers. The training is designed to improve the cross-profession service of the trainees. The Level III classes will be expected to complete within 6 years.

The National Union of Nurses' Association, R.O.C. has accepted the assignment by the Department of Health and planned a curriculum for Level 1 classes between 2011 May and 2011 July. There is a total of 8 sessions of classes and there is an attendance of 1963 people with a passing rate of 1926 people.

\section{Materials and Methods}

The data referenced by this paper is taken from data 
provided by "Long Term Care Trainee Program" organized by National Union of Nurses' Association R.O.C. From May 2011 till July 2011, a total of 8 Level I classes have been organized. Trainees in the training classes will have to complete an assessment before and after the training class as a form of pretest and posttest. Experts and professionals will ensure the difficulty of the pretest and posttest is similar in difficulty through discussions and meetings. The results of the assessments will be linked to the profiles of the trainees to perform analysis.

A total of 1,963 people has joined the training program and 1,926 trainees have passed the posttests and achieve their certificate. However, there are only 851 trainees completing both the pretests and posttests. The important variables will be analyzed through descriptive statistical analysis of the assessment results. The correlation of the variables will also be verified through ANOVA (analysis of variance) and Pearson product-moment correlation coefficient. Finally, the dissimilarities of the trainees in pretest and posttest will be verified using regression statistical analysis. The factors affecting the dissimilarities will then be analyzed.

\section{Results}

There are a total of 1963 people participating in the training program this year and 1926 people have completed the program and achieved their certificate of completion. This shows a passing rate of $98.1 \%$ (Table 1). Among the 8 different categories of health care occupation, occupational therapist and clinical psychologist have a $100 \%$ passing rate and the rest have a passing rate of more than $95 \%$.

$43.4 \%$ (851 out of 1963) of the trainees have completed both the pretest and posttest assessments. They are chosen for analysis to verify the effectiveness of the training courses. Among the 851 trainees chosen for analysis, $87 \%$ are females, thus making the ratio of male to female to be 1:7. This ratio is similar to the gender distribution of the nursing workforce (Table 2). In this research, the average age of the trainees that have completed the training program is 36 -years-old. Nurses and pharmacist takes up the majority of the occupation $(52.6 \%, 12.9 \%)$ and majority of the trainees work in hospitals (54.1\%), followed by care institution (24.6\%).

From the results of the pair-t test shown in Table 3,

Table 1: Passing rate of all occupations.

\begin{tabular}{|l|l|l|l|}
\hline Occupation & Attending people & Passing people & Passing rate \\
\hline Nurse & 1094 & 1071 & 97.9 \\
\hline Pharmacist & 233 & 229 & 98.3 \\
\hline Physician & 38 & 37 & 97.4 \\
\hline Physical therapist & 158 & 157 & 99.4 \\
\hline Occupational therapists & 145 & 145 & 100 \\
\hline Nutritionist & 152 & 145 & 95.4 \\
\hline Social worker & 132 & 131 & 99.2 \\
\hline Clinical psychologist & 11 & 11 & 100 \\
\hline Total & 1963 & 1926 & 98.1 \\
\hline
\end{tabular}

Table 2: Characters of cases.

\begin{tabular}{|l|l|l|}
\hline Variables & \multicolumn{2}{l|}{ Percentage (\%) } \\
\hline Gender $(\mathrm{n}=851)$ & 111 & 87 \\
\hline Male & 740 & 13 \\
\hline Female & & \\
\hline Age $(\mathrm{n}=849)$ & $35.8 \pm 8.26$ & \\
\hline Mean \pm sd & $69 / 21$ & 52.6 \\
\hline Max/min & & 12.9 \\
\hline Occupation $(\mathrm{n}=851)$ & 448 & 1.3 \\
\hline Nurse & 110 & 9.8 \\
\hline Pharmacist & 11 & 7.5 \\
\hline Physician & 83 & 8.6 \\
\hline Physical therapist & 64 & 6.8 \\
\hline Occupational therapists & 73 & 0.5 \\
\hline Nutritionist & 58 & \\
\hline Social worker & 4 & 54.1 \\
\hline Clinical psychologist & & 6.3 \\
\hline Working place $(\mathrm{n}=851)$ & 460 & 5.4 \\
\hline Hospital & 54 & 24.6 \\
\hline Clinic and health care service center & 46 & 9.6 \\
\hline Pharmacy & 209 & \\
\hline Care institutions (Including long term and daily care) & 82 & \\
\hline Others & & \\
\hline
\end{tabular}


Table 3: The result of pair-t test.

\begin{tabular}{|c|c|c|c|c|c|c|c|c|c|}
\hline \multirow[b]{2}{*}{ Variables } & \multicolumn{5}{|c|}{ Pre-test score } & \multicolumn{4}{|c|}{ Post-test score } \\
\hline & Coefficient & S.E. & $\mathbf{T}$ & P-value & & Coefficient & S.E. & $\mathbf{T}$ & P-value \\
\hline Gender & & & & 0.259 & & & & & 0.347 \\
\hline Female & - & - & - & - & & - & - & - & - \\
\hline Male & 1.203 & 1.065 & 1.129 & 0.259 & & -0.699 & 0.742 & -0.942 & 0.347 \\
\hline Age & 0.081 & 0.044 & 1.851 & 0.064 & & 0.093 & 0.030 & 3.078 & 0.002 \\
\hline Time of working (year) & 0.027 & 0.036 & 0.740 & 0.459 & & 0.025 & 0.025 & 0.978 & 0.328 \\
\hline Time of long-term care (year) & 0.215 & 0.055 & 3.916 & $<0.001$ & & 0.056 & 0.038 & 1.452 & 0.147 \\
\hline Occupation & & & & $<0.001$ & & & & & 0.580 \\
\hline Nurse & - & - & - & - & & - & - & - & - \\
\hline Pharmacist & -3.048 & 1.082 & -2.816 & 0.005 & & 0.121 & 0.777 & 0.156 & 0.876 \\
\hline Physician & 8.498 & 3.103 & 2.738 & 0.006 & & -2.197 & 2.227 & -0.987 & 0.324 \\
\hline Physical therapist & 1.912 & 1.222 & 1.565 & 0.118 & & 0.790 & 0.877 & 0.902 & 0.368 \\
\hline Occupational therapists & 4.357 & 1.359 & 3.206 & 0.001 & & 0.537 & 0.975 & 0.551 & 0.582 \\
\hline Nutritionist & -3.694 & 1.284 & -2.878 & 0.004 & & -0.485 & 0.921 & -0.526 & 0.599 \\
\hline Social worker & 5.308 & 1.419 & 3.740 & $<0.001$ & & 1.682 & 1.019 & 1.651 & 0.099 \\
\hline Clinical psychologist & 3.498 & 5.106 & 0.685 & 0.494 & & -2.197 & 3.665 & -0.600 & 0.549 \\
\hline Working place & & & & 0.005 & & & & & 0.009 \\
\hline Hospital & - & - & - & - & & - & - & - & - \\
\hline $\begin{array}{l}\text { Clinic and health care service } \\
\text { center }\end{array}$ & 2.163 & 1.497 & 1.445 & 0.149 & & -1.523 & 1.043 & -1.460 & 0.145 \\
\hline Pharmacy & -3.236 & 1.609 & -2.012 & 0.045 & & -0.231 & 1.122 & -0.206 & 0.837 \\
\hline $\begin{array}{l}\text { Care institution (including long } \\
\text { term and daily care) }\end{array}$ & 2.322 & 0.868 & 2.674 & 0.008 & & 1.749 & 0.606 & 2.888 & 0.004 \\
\hline Others & 0.902 & 1.247 & 0.724 & 0.470 & & -0.371 & 0.870 & -0.427 & 0.669 \\
\hline
\end{tabular}

${ }^{*} \mathrm{P}$-value $<0.05$.

Table 4: Multiple regression of pre-test score.

\begin{tabular}{|c|c|c|c|c|c|}
\hline Variables & Coefficient & S.E. & $\mathbf{T}$ & P-value & \\
\hline \multicolumn{6}{|l|}{ Time of long-term care (year) } \\
\hline $0 \sim 2$ & - & - & - & - & \\
\hline $2 \sim 5$ & 3.729 & 0.882 & 4.229 & $<0.001$ & * \\
\hline 5 & 5.560 & 0.860 & 6.463 & $<0.001$ & * \\
\hline \multicolumn{6}{|l|}{ Occupation } \\
\hline Nurse & - & - & - & - & \\
\hline Pharmacist & -0.695 & 1.315 & -0.529 & 0.597 & \\
\hline Physician & 8.127 & 2.964 & 2.742 & 0.006 & * \\
\hline Physical therapist & 2.838 & 1.198 & 2.370 & 0.018 & * \\
\hline Occupational therapists & 5.361 & 1.329 & 4.034 & $<0.001$ & * \\
\hline Nutritionist & -3.245 & 1.229 & -2.640 & 0.008 & * \\
\hline Social worker & 5.214 & 1.390 & 3.752 & $<0.001$ & * \\
\hline Clinical psychologist & 4.867 & 4.852 & 1.003 & 0.316 & \\
\hline \multicolumn{6}{|l|}{ Working place } \\
\hline Hospital & - & - & - & - & \\
\hline Clinic and health care service center & 2.475 & 1.414 & 1.750 & 0.080 & * \\
\hline Pharmacy & -1.304 & 1.882 & -0.693 & 0.489 & \\
\hline Care institution (including long term and daily care) & 0.612 & 0.885 & 0.692 & 0.489 & \\
\hline Others & -0.129 & 1.199 & -0.107 & 0.915 & \\
\hline
\end{tabular}

${ }^{*} \mathrm{P}$-value $<0.05$.

it can be deduced that there is a significant difference in the pretest of trainees with different time of long-term care, occupation and working place. Moreover, trainees with different age and working place have a significant difference in their posttest results. However, working time and gender difference has no influence in the pretest and posttest results.

Further analysis is performed on pretest results, posttest results and the difference score of the two tests to understand the factors influencing the results and score (Table 4 and Table 5). While controlling other factors, the trainees' pretest results are shown to be closely related to time of long-term care, occupation difference and working venue. Trainees who are involved in care-related work for a longer period of time tend to have a better pretest score than those involved for a shorter period of time. Moreover, pretest results are also showing significant difference in trainees with different occupations. Physicians, physical therapist, occupational therapist and social workers are showing 
Table 5: Multiple regression of post-test score.

\begin{tabular}{|c|c|c|c|c|}
\hline Variables & Coefficient & S.E. & $\mathbf{T}$ & P-value \\
\hline Age & 0.063 & 0.032 & 1.951 & 0.051 \\
\hline \multicolumn{5}{|l|}{ Time of long-term care (year) } \\
\hline $0 \sim 2$ & - & - & - & - \\
\hline $2 \sim 5$ & 0.756 & 0.645 & 1.172 & 0.242 \\
\hline $5 \sim$ & 0.966 & 0.667 & 1.450 & 0.148 \\
\hline \multicolumn{5}{|l|}{ Working place } \\
\hline Hospital & - & - & - & - \\
\hline Clinic and health care service center & -0.991 & 1.031 & -0.961 & 0.337 \\
\hline Pharmacy & -0.619 & 1.132 & -0.547 & 0.585 \\
\hline Care institution (including long term and daily care) & 1.501 & 0.625 & 2.400 & 0.017 \\
\hline Others & -0.214 & 0.856 & -0.250 & 0.803 \\
\hline
\end{tabular}

${ }^{*}$ P-value $<0.05$.

Table 6: Multiple regression of the difference with pre-test and post-test score.

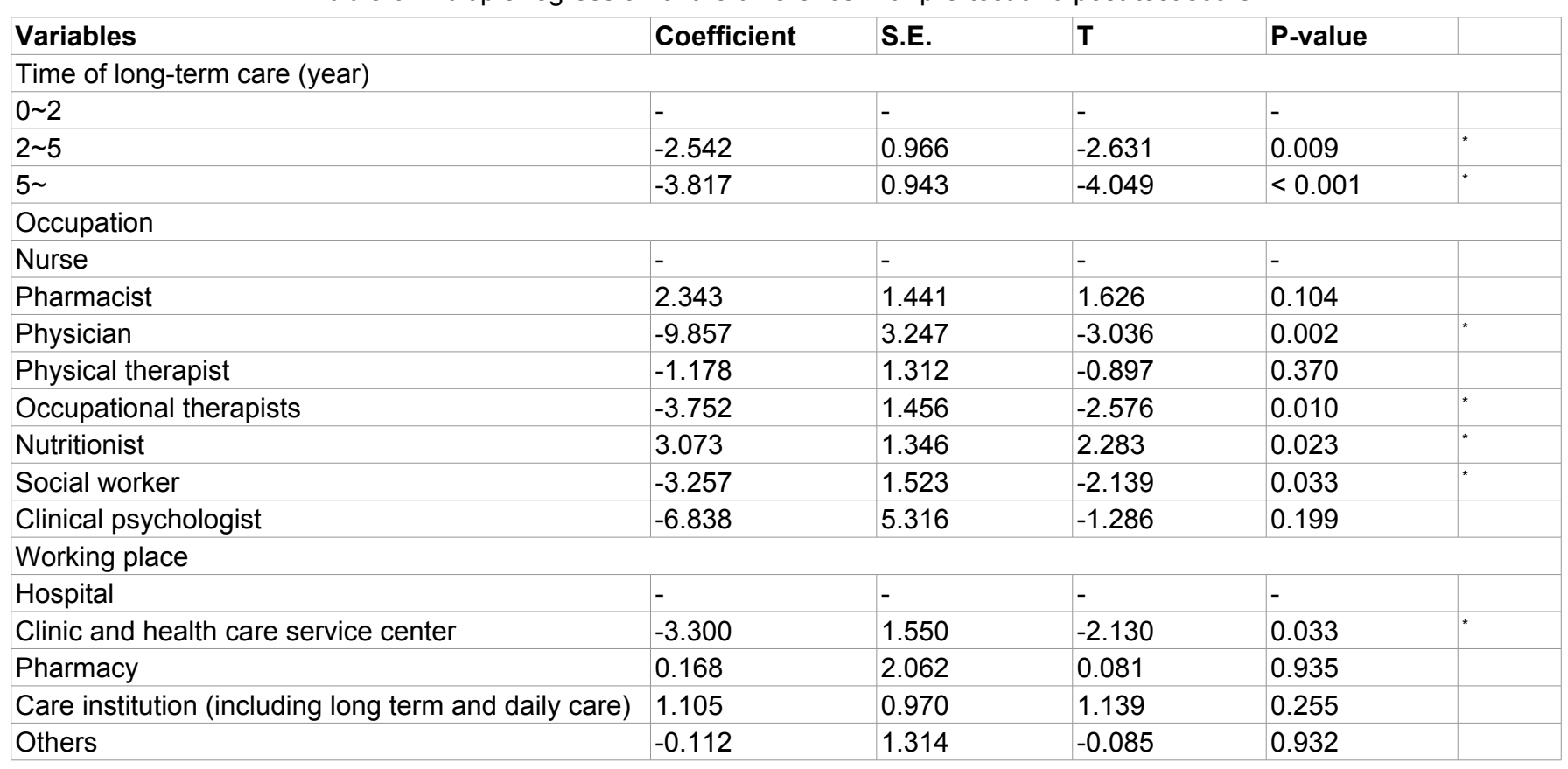

${ }^{*} \mathrm{P}$-value $<0.05$.

better performance in pretest assessments with nutritionist performing worse. Finally, trainees who worked in clinics and health care centers are performing better than trainees who worked in other places. Unlike pretest results, posttest results are showing correlation with only working place. Trainees who worked in care institutions have a better posttest score than the rest of the trainees.

This paper performs multiple regression analysis on the difference with pretest score and posttest score to understand the degree of improvement before and after the training course. Analysis results shown that time of long-term care, occupation and working place have different influence level on the degree of improvement. Trainees who have spent a longer time in long-term care have a lower degree of improvement. Trainees who spent more than 5 years in long-term care have the least amount of improvement. (P-value < 0.001) (Table 6). As for occupation, nutritionist has the highest degree of improvement as compared to other professions. Among the rest of the occupations, physicians, occupational therapist and social workers have the least im- provement. Lastly, trainees who worked in clinics and health care service have significant lower improvement as compared to other trainees.

\section{Discussions and Conclusions}

Trainee's pretest scores can be postulated as the prior knowledge of the trainees when they joined the training program. Due to the trainees coming from various fields and workplace related to medical services, they are exposed to different information about long-term care. This has caused the trainees to have different prior knowledge. Trainees working in clinics and care service centers have a significant advantage in their knowledge of long-term care as compared to trainees working in other fields including care institutions. However, this trend is not followed in the analysis of posttest results. Trainees who work in care institutions perform significantly better than other trainees after going through the training courses. This is possibly due to the similarity in the nature of their work and the contents of the training course, allowing them to have an outstanding outcome of their training. 
The saying that knowledge takes time to build up can be justified in the analysis of pretest results. Trainees who have been in the work field for a longer time has a better prior knowledge but their improvement after the training course is lower.

Regression analysis results of the posttest have indicated that trainees perform the same regardless of their age, work years in long-term care and occupation. However, trainees who worked in care institutions perform better than other trainees who worked in other places. Finally, after going through the training courses, the learning outcome of the trainees from various occupations is consistent.

This paper conducted further verification of the rate of improvement of the trainees after going through the training courses. Verification results are similar to the conclusion that trainees with better prior knowledge have a smaller improvement. The rate of improvement of the trainees is affected by factors such as the working years, occupation and working place.

From the analysis data of this paper, Level 1 classes have reached a satisfactory level in terms of the passing rate and learning outcome of the trainees. However, difference in posttest and pretest results of trainees from different occupations requires further investigations. The distribution of correct answers and wrong answers by trainees of different occupation explains the difference in the passing rate and the pretest results.
The materials of the training course are localized to suit the Taiwanese long-term care related facilities and law. Therefore, the outcome of the long-term care training courses is unable to be used for further analysis to compare with long-term care training courses from foreign countries. However, the research results can be used as a reference for organizations trying to plan new training courses related to long-term care.

\section{Acknowledgement}

This research was supported by The Department of Health in Taiwan (99M4204).

\section{References}

1. Suwu Chong Wu, Tung Liang Chiang (1995) Long-Term Care in Taiwan: Issues and Directions. Chinese Journal of Public Health 14: 246-255.

2. Shu Fen Chen, Sue Wen Teng (2010) The Development of the Long-Term Care Service System in Taiwan. Hu Li Za Zhi 57: 5-10.

3. Yin Yin Tsai, Li Chan Lin, Yue Chune Lee (2011) A Commentary on a Ten-Year Plan for Long-term Care in Taiwan: A Nursing Perspective. Journal of Chang Gung Institute of Technology 14: 25-31.

4. Meei Shiow Lu (2011) Long term care professional manpower training program achievements report. 2010 Project commissioned by the Department of Health Taiwan, The National Union of Nurses' Associations, R.O.C. 